\title{
Serum Myostatin Levels are Elevated in Overweight Patients
}

\author{
Hui J. Zhu\#, Hong B. Yang\#, Xiang Q. Wang, Hui Pan, Dian X. Zhang, Nai S. Li, Lin J. Wang and \\ Feng Y. Gong ${ }^{*}$
}

Department of Endocrinology, Key Laboratory of Endocrinology of Ministry of Health, The Translational Medicine Center of PUMCH, Peking Union Medical College Hospital, Chinese Academy of Medical Sciences \& Peking Union Medical College, Beijing, China

\begin{abstract}
Objective: Myostatin has recently been proposed as an important factor that not only regulates skeletal muscle mass, but also body fat mass. The aim of our study is to explore serum myostatin levels in overweight patients and its association with metabolic-related characteristics.

Methods: 40 overweight patients and 40 normal weight controls were recruited, and serum myostatin were measured by ELISA methods and the relationships between myostatin and metabolic-related parameters were investigated.

Results: Serum myostatin concentrations were significantly increased in overweight patients compared with normal weight controls $(10.99 \pm 1.99$ vs. $9.75 \pm 0.96 \mathrm{ng} / \mathrm{ml}, \mathrm{P}=0.001)$ and positively correlated with body weight $(\mathrm{r}=0.272$, $\mathrm{P}=0.015)$, BMI $(\mathrm{r}=0.263, \mathrm{P}=0.018)$, waist circumference $(\mathrm{r}=0.291, \mathrm{P}=0.009)$, hip circumference $(\mathrm{r}=0.336, \mathrm{P}=0.002)$ and TNF- $\alpha(r=0.611, P<0.001)$ in all subjects. Contrarily, serum adiponectin levels were negatively associated with body weight $(r=-0.270, P=0.018)$, waist-to-hip ratio (WHR) $(r=-0.253, P=0.027)$, TG $(r=-0.235, P=0.040)$, ALT $(r=-0.268$, $\mathrm{P}=0.019)$, uric acid (UA) $(\mathrm{r}=-0.262, \mathrm{P}=0.021)$ and positively correlated with $\mathrm{HDL}(\mathrm{r}=0.454, \mathrm{P}<0.001)$.
\end{abstract}

Conclusion: Serum myostatin levels in overweight patients are notably increased and positively correlated with BMI, body weight, waist and hip circumference, TNF- $\alpha$, suggesting myostatin is a metabolic regulatory factor.

Keywords: Adiponectin, myostatin, overweight, TNF- $\alpha$.

\section{INTRODUCTION}

Obesity is associated with genetic, environmental and lifestyle factors that include a sedentary lifestyle and high caloric diet. A growing body of evidence has found that overweight and obesity are the main causes of co-morbidities which can result in further morbidity and mortality $[1,2]$. Recently, obesity is recognized to be associated with endocrine abnormalities that are triggered by some secreted proteins, a special class of biologically active molecules, which is released into circulation by several organs especially including adipose tissue and skeletal muscle [3]. Some of these secreted proteins were demonstrated to have associations with insulin resistance and were involved in the progression of diabetes mellitus, hypertension, cardiovascular disease and cancer, so they were considered as biomarkers [4, 5].

Myostatin, also known as growth differentiation factor 8, is a biological active molecules which is predominantly produced by skeletal muscle. Human myostatin is $26 \mathrm{kDa}$

*Address correspondence to this author at the Department of Endocrinology, Peking Union Medical College Hospital, 1\# Shuaifuyuan, Wangfujing, Beijing, 100730, China; Tel: 8610 69155100;

Fax: 861069155073 ; E-mails: fygong@sina.com, fygong@aliyun.com

${ }^{\#}$ These authors contribute equally protein, and its gene comprises of three exons and two introns, mapping to chromosomal region 2q32.2 [6-8]. Myostatin was firstly found as a muscle development inhibitory factor due to the evidence that mutations in myostatin gene lead to a hypermuscular phenotype in mice and cattle [9], and myostatin gene knockout mice present a notable increase in myogenesis $[10,11]$. In recent years, substantial evidence from literature shows that myostatin is related with obesity. Fat accumulation and fat mass were significantly reduced, and insulin sensitivity was greatly improved in myostatin-deficient mice or inhibition in the role of myostatin in the muscle of mice [12]. The similar results were gotten from the studies performed by Mitchell et al who demonstrated that the percentage of body fat in mice was significantly decreased after transgenic over-expression myostatin pro domain which would inhibit the action of myostatin [13]. Our recent studies also showed that myostatin gene SNP in rs3791783 (A/G) site is correlated with obesity in Chinese north Han human subjects. Subjects with AA genotype will have higher risk suffered from overweight or obesity than those with GG genotype [8]. All of these results show that myostatin is associated with fat accumulation and adipogenesis in addition to its function in regulation of muscle development and growth.

To date, there have been no studies that evaluated whether serum levels of myostatin are related with obesity in 
Chinese North Han population. Therefore, in this study, we investigate serum levels of myostatin in overweight patients and its association with related clinical and biochemical characteristics. Our results showed that serum myostatin levels were significantly increased in overweight patients, and positively correlated with body weight, BMI, waist and hip circumference and TNF- $\alpha$.

\section{SUBJECTS AND METHODS}

\subsection{Study Participants, Clinical and Biochemical Characteristics}

Forty overweight patients and forty normal weight healthy controls were recruited from outpatient in Peking Union Medical College Hospital, and all subjects underwent physical examination, anthropometric measurements and biochemical screening. Body weight, height, waist circumference and hip circumference were measured as we described previously [14]. Body mass index (BMI, $\mathrm{kg} / \mathrm{m}^{2}$ ) was calculated as weight in kilogram divided by squared height in meter and waist-to-hip ratio (WHR) was calculated as waist circumference divided by hip circumference. All blood samples were collected from an antecubital vein between 8:00 and 9:00 A.M. following an overnight fasting. Total cholesterol (TC), triglycerides (TG), high-density lipoprotein cholesterol (HDL-c), low-density lipoprotein cholesterol (LDL-c), fasting blood glucose (FBG), creatinine $(\mathrm{Cr})$, uric acid (UA), aspartate aminotransferase (AST), alanine aminotransferase (ALT), blood urea nitrogen (BUN) were measured by routine automated laboratory methods. The overweight patient group had simple or primary obesity aged from 25 to 60 years, excluding secondary overweight from other diseases. The inclusion criteria is as the following: (1) Body mass index (BMI) $\geq 25 \mathrm{~kg} / \mathrm{m}^{2}$; (2) Normal liver function [ALT (U/L) <40, AST (U/L) <40] and renal function $[\mathrm{Cr}(\mathrm{umol} / \mathrm{L})<84$, BUN (mmol/L) $<7.14]$. (3) Systolic blood pressure (SBP) $<140 \mathrm{mmHg}$ and diastolic blood pressure (DBP) $<90 \mathrm{mmHg}$ ]. The study was approved by the Ethics Committee of Peking Union Medical College Hospital. All participants gave written informed consent before their participation in the study.

\subsection{Assays of Serum Myostatin and Other Adipokines}

Blood samples were centrifuged at $3000 \mathrm{~g}$ for $10 \mathrm{~min}$ at $4^{\circ} \mathrm{C}$ and serum aliquots were stored at $-80{ }^{\circ} \mathrm{C}$ until analysis was performed. Serum myostatin, total adiponectin and tumor necrosis factor- $\alpha$ (TNF- $\alpha)$ levels were determined by commercially available human ELISA kit (Shanghai Westang Bio-tech Co.Ltd for myostatin, Adipo Bioscience, INC, USA for adiponectin and R\&D system Quantikine ELISA for TNF- $\alpha$ ) according to the manufacture's instruction. All antibodies used in these assays were specific for human targeted factors with no detectable cross reactivity to other factors and genus. All samples were assayed in duplicate and random order, and laboratory measurements were performed blinded to the readings of BMI and other items. The intra-assay and inter-assay coefficient of variations were $5.8 \%$ and $8.4 \%$ for myostatin, $2.4 \%$ and
$6.2 \%$ for adiponectin, $1.8 \%$ and $5.6 \%$ for TNF- $\alpha$, respectively.

\subsection{Data Analysis}

Results were expressed as mean \pm standard deviation (SD). All statistical computations were run on SPSS 13.0 for Windows (SPSS Inc, Chicago, IL, USA). The Shapiro-Wilk normality test was used for all continuous variables to characterize the data distribution. Skewed data were logtransformed and Mann-Whitney U test was used if data were still not normally distributed for further analysis. Student's $t$ test was used to evaluate differences between the two study groups in normally distributed continuous variables. Correlations among the study variables were tested using partial correlation coefficient controlling for age and gender. $\mathrm{P}<0.05$ was considered as statistically significant in all analyses.

\section{RESULTS}

\subsection{General Characteristics}

The differences of anthropometric and laboratory measurements in normal weight controls and overweight patients are displayed in Table 1. As expected, overweight patients had higher weight $(\mathrm{P}<0.001)$, BMI $(\mathrm{P}<0.001)$, waist $(\mathrm{P}<0.001)$ and hip $(\mathrm{P}<0.001)$ circumferences, WHR $(\mathrm{P}=0.004)$, and FBG $(\mathrm{P}<0.001)$ than normal weight controls. However, there was no significant difference with regard to age, gender, SBP, DBP, ALT, AST, Cr, BUN, UA, TC, TG, HDL-c and LDL-c between these two groups.

Student's t test was used to evaluate differences between the two study groups for all parameters except for UA. UA is not normally distributed and Mann-Whitney U test was used.

\subsection{Serum Levels of Myostatin, Adiponectin and TNF-a in Overweight Patients and Normal Weight Controls}

Serum levels of myostatin, adiponectin and TNF- $\alpha$ in healthy controls and overweight patients were determined by commercial available ELISA kits. As shown in Table 1, overweight patients presented $12.7 \%$ higher serum myostatin $(10.99 \pm 1.99$ vs. $9.75 \pm 0.96 \mathrm{ng} / \mathrm{ml}, \quad \mathrm{P}=0.001)$ and $31.2 \%$ higher serum TNF- $\alpha \quad(3.46 \pm 1.57$ vs. $2.38 \pm 0.99 \mathrm{pg} / \mathrm{ml}$, $\mathrm{P}=0.001)$ when compared with controls. This increased phenomenon was more obvious in women when compared by gender. There is no significant difference in serum adiponectin levels either in total groups or comparison by gender (Table 1).

3.3. Correlations and Regression of Serum Myostatin, Adiponectin and TNF- $\alpha$ Levels with Anthropometric and Biochemical Items in Overweight Patients and Normal Weight Controls

Partial correlation coefficient was calculated to analyze the relationship between myostatin, adiponectin, TNF- $\alpha$ and metabolic-related items controlling for age and gender in overweight patients and normal weight controls. As depicted 
Table 1. Various items comparison in overweight patients and normal weight controls.

\begin{tabular}{|c|c|c|c|}
\hline Demographics & Overweight & Control & P-value \\
\hline $\mathrm{M} / \mathrm{F}(\mathrm{n})$ & $9 / 31(40)$ & $16 / 24(40)$ & 0.094 \\
\hline Age (y) & $53.6 \pm 3.6$ & $53.0 \pm 7.9$ & 0.692 \\
\hline Anthropometry & Overweight & Control & P-value \\
\hline Weight (kg) & $70.5 \pm 8.1$ & $62.1 \pm 9.8$ & $<0.001$ \\
\hline male & $77.7 \pm 10.7$ & $70.1 \pm 8.9$ & 0.066 \\
\hline female & $68.4 \pm 5.9$ & $57.4 \pm 7.2$ & $<0.001$ \\
\hline BMI $\left(\mathrm{kg} / \mathrm{m}^{2}\right)$ & $28.2 \pm 2.5$ & $22.9 \pm 2.1$ & $<0.001$ \\
\hline male & $27.7 \pm 3.0$ & $23.5 \pm 1.6$ & $<0.001$ \\
\hline female & $28.4 \pm 2.4$ & $22.4 \pm 2.2$ & $<0.001$ \\
\hline Waist (cm) & $88.7 \pm 6.3$ & $78.6 \pm 8.1$ & $<0.001$ \\
\hline male & $93.3 \pm 7.7$ & $83.5 \pm 6.3$ & 0.002 \\
\hline female & $87.4 \pm 5.3$ & $75.0 \pm 7.4$ & $<0.001$ \\
\hline Hip (cm) & $100.8 \pm 5.5$ & $93.2 \pm 5.3$ & $<0.001$ \\
\hline male & $101.2 \pm 4.9$ & $95.5 \pm 4.6$ & 0.004 \\
\hline female & $100.5 \pm 5.7$ & $91.6 \pm 5.1$ & $<0.001$ \\
\hline WHR & $0.88 \pm 0.06$ & $0.84 \pm 0.05$ & 0.004 \\
\hline male & $0.92 \pm 0.07$ & $0.87 \pm 0.05$ & 0.059 \\
\hline female & $0.87 \pm 0.05$ & $0.82 \pm 0.05$ & 0.001 \\
\hline $\mathrm{SBP}(\mathrm{mmHg})$ & $120.2 \pm 6.4$ & $122.4 \pm 14.2$ & 0.396 \\
\hline $\mathrm{DBP}(\mathrm{mmHg})$ & $76.4 \pm 4.7$ & $75.2 \pm 11.1$ & 0.507 \\
\hline Biochemical items & Overweight & Control & P-value \\
\hline FBG $(\mathrm{mmol} / \mathrm{L})$ & $5.56 \pm 1.18$ & $4.86 \pm 0.44$ & $<0.001$ \\
\hline male & $5.56 \pm 0.83$ & $4.99 \pm 0.89$ & 0.131 \\
\hline female & $5.56 \pm 1.27$ & $4.89 \pm 0.43$ & 0.015 \\
\hline $\operatorname{ALT}(\mathrm{U} / \mathrm{L})$ & $24.9 \pm 20.6$ & $21.2 \pm 12.8$ & 0.992 \\
\hline AST (U/L) & $22.2 \pm 6.4$ & $22.0 \pm 9.3$ & 0.653 \\
\hline $\mathrm{Cr}(\mathrm{umol} / \mathrm{L})$ & $74.7 \pm 13.8$ & $78.7 \pm 16.3$ & 0.234 \\
\hline BUN (mmol/L) & $5.06 \pm 1.15$ & $5.35 \pm 1.61$ & 0.361 \\
\hline $\mathrm{UA}(\mathrm{mmol} / \mathrm{L})$ & $247.3 \pm 78.7$ & $245.6 \pm 87.2$ & 0.926 \\
\hline $\mathrm{TC}(\mathrm{mmol} / \mathrm{L})$ & $5.09 \pm 1.05$ & $4.80 \pm 0.78$ & 0.167 \\
\hline $\mathrm{TG}(\mathrm{mmol} / \mathrm{L})$ & $1.53 \pm 1.02$ & $1.25 \pm 0.58$ & 0.131 \\
\hline HDL-c (mmol/L) & $1.32 \pm 0.27$ & $1.38 \pm 0.42$ & 0.430 \\
\hline LDL-c (mmol/L) & $3.18 \pm 0.82$ & $2.91 \pm 0.69$ & 0.120 \\
\hline
\end{tabular}


Table 1. contd..

\begin{tabular}{|c|c|c|c|}
\hline Adipkines & Overweight & Control & P-value \\
\hline Myostatin (ng/ml) & $10.99 \pm 1.99$ & $9.75 \pm 0.96$ & 0.001 \\
\hline female & $10.9 \pm 1.85$ & $9.58 \pm 0.90$ & 0.002 \\
\hline Adiponectin $(\mu \mathrm{g} / \mathrm{ml})$ & $4.89 \pm 1.78$ & $5.10 \pm 2.46$ & 0.673 \\
\hline female & $5.23 \pm 1.77$ & $5.39 \pm 2.00$ & 0.755 \\
\hline TNF- $\alpha(\mathrm{pg} / \mathrm{ml})$ & $3.46 \pm 1.57$ & $2.38 \pm 0.99$ & $<0.001$ \\
\hline male & $3.48 \pm 1.68$ & $2.86 \pm 0.95$ & 0.238 \\
\hline
\end{tabular}

BMI: body mass index; WHR: waist-to-hip ratio; SBP: systolic blood pressure; DBP: diastolic blood pressure; FBG: fasting blood glucose; ALT: alanine aminotransferase; AST: aspartate aminotransferase; Cr: creatinine; BUN: blood urea nitrogen; UA: uric acid; TC: total cholesterol; TG: triglycerides; HDL-c: high-density lipoprotein cholesterol; LDL-c: low-density lipoprotein cholesterol.

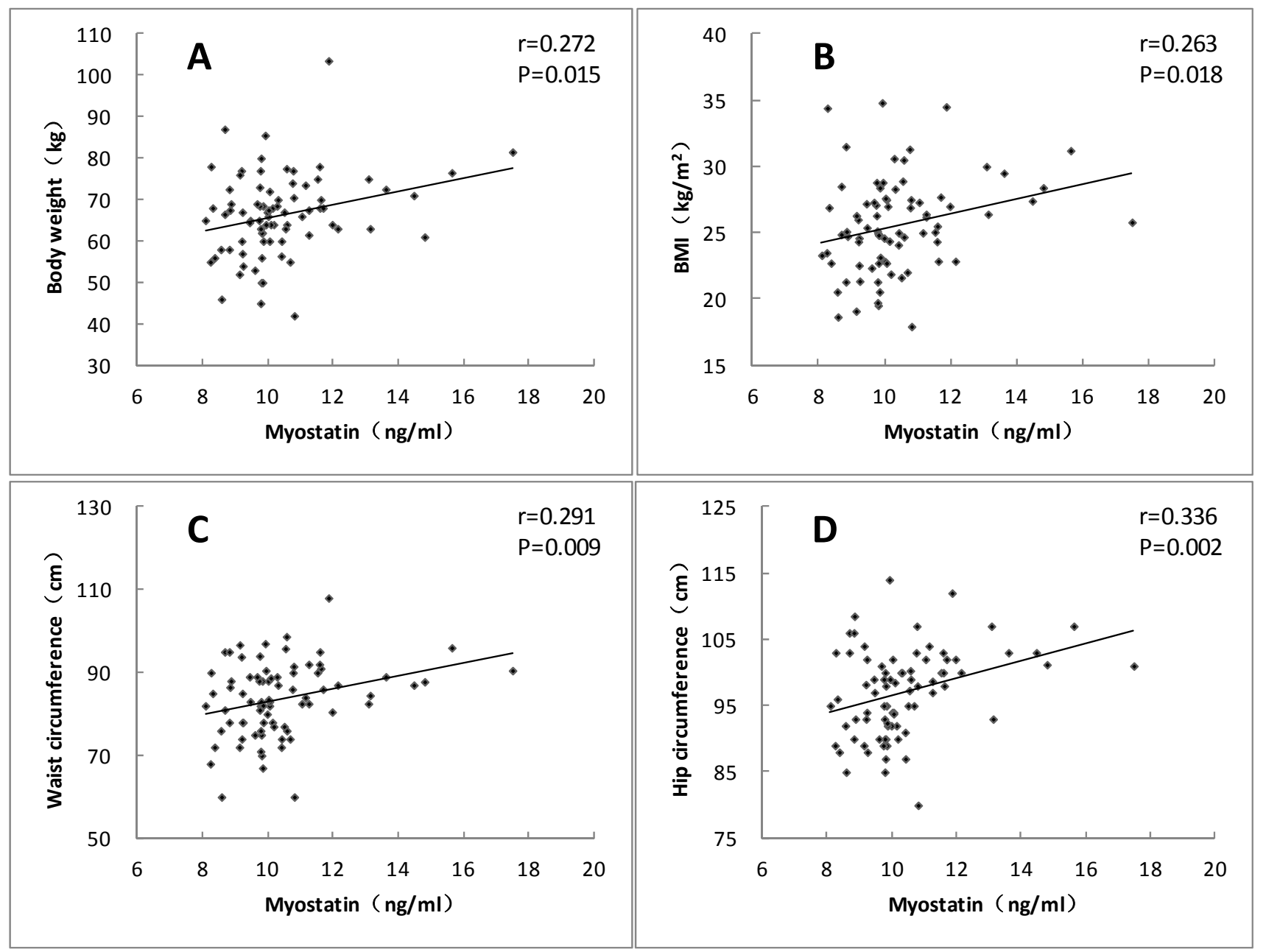

Fig. (1). Correlation between serum myostatin levels and body weight (A), BMI (B), waist (C) and hip circumference (D) in normal weight controls and overweight patients.

in Fig. (1), serum myostatin level was positively correlated with body weight $(\mathrm{r}=0.272, \mathrm{P}=0.015)$, BMI $(\mathrm{r}=0.263$, $\mathrm{P}=0.018)$, waist $(\mathrm{r}=0.291, \mathrm{P}=0.009)$ and hip circumference
( $\mathrm{r}=0.336, \mathrm{P}=0.002)$, respectively, when all subjects were considered together. Similarly, serum TNF- $\alpha$ level was also positively correlated with $\mathrm{BMI}(\mathrm{r}=0.245, \mathrm{P}=0.026)$ 

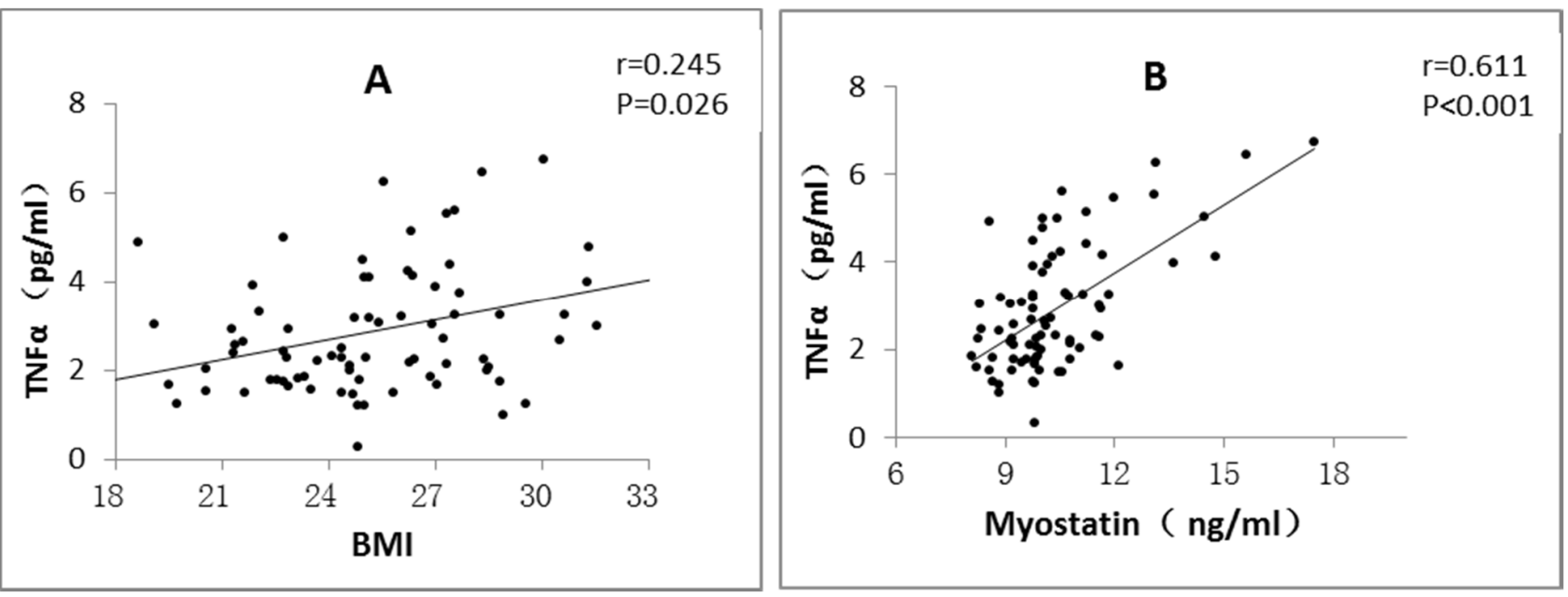

Fig. (2). Correlation between serum TNF- $\alpha$ levels and BMI (A), myostatin (B) in normal weight controls and overweight patients.

(Fig. 2A). On the contrary to myostatin and TNF- $\alpha$, serum adiponectin level was inversely correlated with body weight $(\mathrm{r}=-0.270, \mathrm{P}=0.018)$, WHR $(\mathrm{r}=-0.253, \mathrm{P}=0.027)$, TG $(\mathrm{r}=-0.235, \mathrm{P}=0.040)$, ALT $(\mathrm{r}=-0.268, \mathrm{P}=0.019)$, UA $(\mathrm{r}=-0.262, \mathrm{P}=0.021)$, and positively, with moderate strength, correlated with HDL $(\mathrm{r}=0.454, \mathrm{P}<0.001)$ in all subjects (Fig. 3). Interestingly, a significant positive relationship was found between myostation and TNF- $\alpha$ $(\mathrm{r}=0.611, \mathrm{P}<0.001)$ among these three adipokines in all subjects (Fig. 2B). Furthermore, the relationships between myostatin, adiponectin, TNF- $\alpha$ and metabolic-related items still existed when overweight patients and normal weight controls were considered separately. Both myostatin and TNF- $\alpha$ levels were positively associated with BUN in overweight patients $(\mathrm{r}=0.358, \mathrm{P}=0.024 ; \mathrm{r}=0.454$, $\mathrm{P}=0.003$ ), and positively associated with UA in normal weight controls $(\mathrm{r}=0.334, \mathrm{P}=0.035 ; \mathrm{r}=0.320, \mathrm{P}=0.039)$.

Furthermore, multiple linear regression was performed to determine independent variables that contribute to serum myostatin levels. Our results showed that waist circumference and TNF- $\alpha$ were independent contributors to circulating myostatin levels after adjusting the age, gender and BMI in all subjects (all $\mathrm{P}<0.05$ ). The standardized coefficient Beta is 0.214 for waist circumference and 0.328 for TNF- $\alpha($ all $\mathrm{P}<0.05)$.

\section{DISCUSSION}

It has been reported that myostatin is a secreted protein that acts as a negative regulator of skeletal muscle development and growth. Animals with myostatin gene loss of function by genetic mutations have dramatically increased skeletal muscle mass, which is due to hyperplasia and hypertrophy of skeletal muscle fibers [15, 16]. Recent studies demonstrated that myostatin is associated with obesity and fat accumulation. In the current study, we found for the first time that serum myostatin levels in overweight patients were higher than normal weight controls in Chinese North Han subjects, and were positively correlated with body weight, BMI, waist and hip circumference in all subjects. In agreement with our results, Hittel et al. reported that circulating myostatin protein levels were increased in obese human subjects, which were subsequently decreased by $37 \%$ following 6 months of moderate aerobic exercise training in North American population. Myostatin mRNA levels of muscle biopsies were also reduced in obese human patients following weight loss due to either biliopancreatic diversion or gastric bypass surgery in North American population $[17,18]$. In addition, studies performed by Wang et al. [19] demonstrated that female subjects showed higher myostatin levels than male subjects in heath people. However, there was no difference in myostatin level by gender in our study. One explanation may be the different population. Our population were come from Chinese North District and Wang's population were from Chinese South District.

Adiponectin, a $29 \mathrm{kDa}$ adipocyte protein, which displays a variety of protective actions on obesity-induced pathological conditions $[20,21]$, has been presented decreased in obesity patients in many studies [22]. In our present study, we found that serum total adiponectin levels were inversely correlated with body weight, WHR, TG and UA, respectively, and positively correlated with HDL in overweight patients and normal weight controls although serum total adiponectin levels were not significant different between these two groups. A similar negative association between serum levels of adiponectin and obesity-related items has been shown in healthy subjects [23] and in nondiabetic subjects with varying degrees of obesity and insulin resistance [24]. In our present study, we also found an inverse relationship between adiponectin and ALT in all subjects although their ALT levels were still in normal range [25]. The similar results were observed in a study of type 2 diabetes patients performed by Liu et al. [26] who found that mean ALT levels showed a progressive decrease as high molecular weight (HMW) adiponectin levels increased after adjustment for age, gender and diabetes status. All these findings suggested that adiponectin may play a protective role in obesity-induced disorders. Unfortunately, any correlations between myostatin and adiponectin were found in our study. A large sample study needs to be done to elucidate this question in the future. 


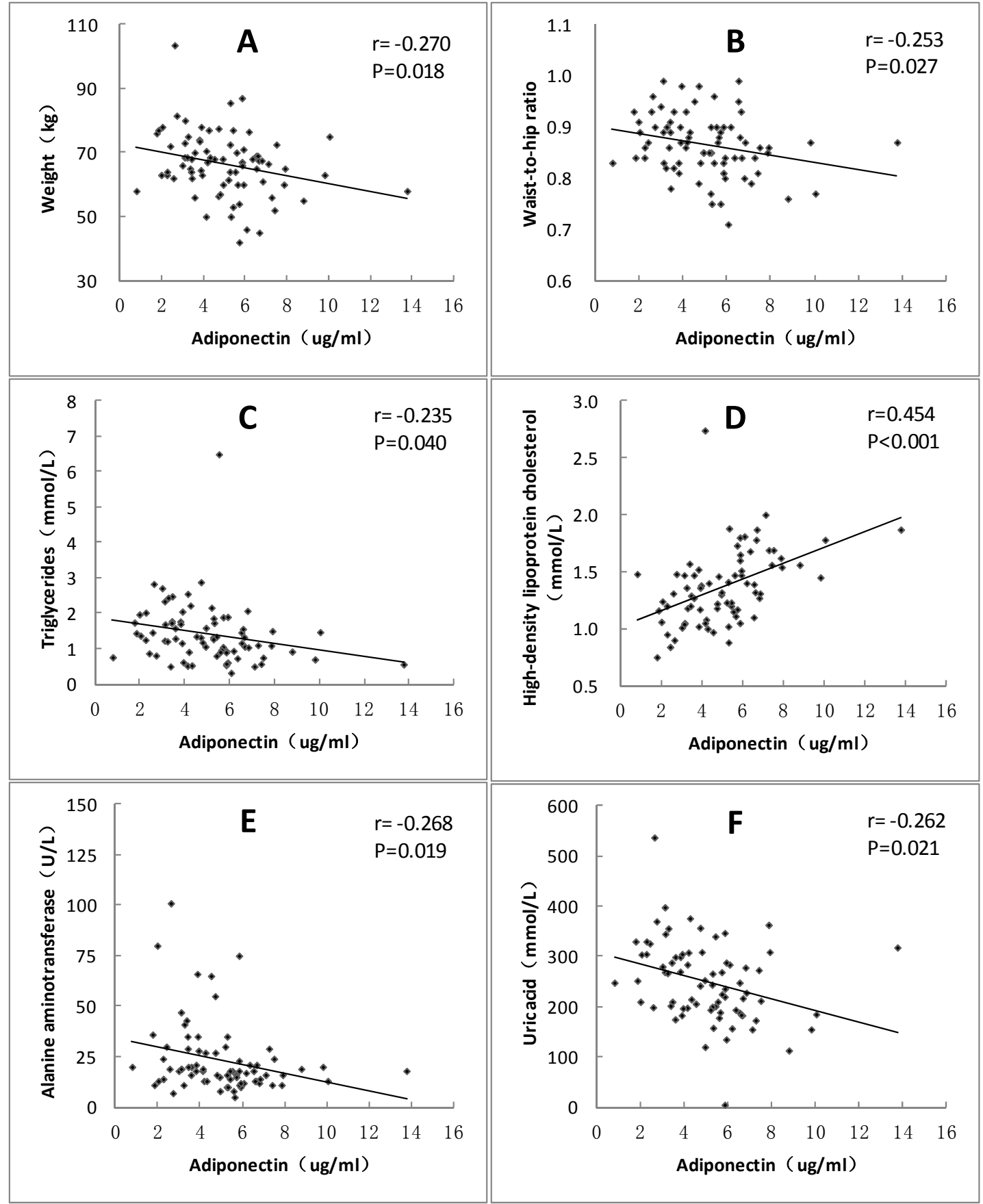

Fig. (3). Correlation between serum adiponectin levels and weight (A), Waist-to-hip (B), Triglycerides (C), High-density lipoprotein cholesterol (D), Aalanine aminotransferase (E) and Uric acid (F) in normal weight controls and overweight patients.

In consistent with myostatin, serum TNF- $\alpha$ levels were higher in overweight patients as compared with normal controls and positively correlated with BMI. TNF- $\alpha$ is an inflammation promoter and plays an important role in the development of obesity and diabetes. We found for the first time serum myostatin is positively correlated with TNF- $\alpha$ in all subjects. Similarly, Wilkes et al. [27] found that circulating TNF- $\alpha$ levels and TNF- $\alpha$ expression in adipose and muscle of myostatin gene knockout (Mstn Ln/Ln) mice with high lean, low-fat body compositions compared with wild types were significantly decreased when compared with wild type mice, and the treatment of mice with myostatin increased plasma TNF- $\alpha$ levels accompanying insulin resistance. All these findings implied that myostatin was involved in the occurrence and development of obesity and its related disorders through crosstalks with proinflammatory cytokine TNF- $\alpha$.

\section{STRENGTHS AND LIMITATIONS}

Our study firstly reported that the serum myostatin levels were higher in overweight patients in comparison with 
normal weight controls, and negatively correlated with serum TNF- $\alpha$ in Chinese North Han subjects. This preliminary result needs to be validated in the larger samples and other ethical groups. Further efforts should also be undertaken in cell levels to recognize the biological role of myostatin in obesity and its related disorders.

\section{CONCLUSION}

In summary, serum myostatin levels are notably augmented in overweight patients, and were positively related with body weight, BMI, waist and hip circumference in Chinese North Han subjects. These findings further confirm the relationship between myostatin and obesity. Further prospective studies are needed to be done to better exclaim the role of myostatin in metabolic-related disorders.

\section{CONFLICT OF INTEREST}

The authors confirm that this article content has no conflicts of interest.

\section{ACKNOWLEDGEMENTS}

The study was supported by grants from the National Natural Science Foundation of China (No.30600836 for Zhu HJ, Nos.30540036, 30771026, 81370898 for Gong FY), the Beijing Natural Science Foundation (No. 7082079 for Gong FY), the National Key Program of Clinical Science (WBYZ2011-873 for Gong FY and Zhu HJ) and PUMCH foundation (2013-020 for Gong FY).

\section{REFERENCES}

[1] Haslam DW, James WP. Obesity. Lancet 2005; 366(9492): $1197-$ 209.

[2] McTigue KM, Hess R, Ziouras J. Obesity in older adults: a systematic review of the evidence for diagnosis and treatment. Obesity (Silver Spring) 2006; 14(9): 1485-97.

[3] Antuna-Puente B, Feve B, Fellahi S, Bastard JP. Adipokines: the missing link between insulin resistance and obesity. Diabetes Metab 2008; 34(1): 2-11.

[4] Zhu HJ, Ding HH, Deng JY, et al. Inhibition of preadipocyte differentiation and adipogenesis by zinc-a2-glycoprotein treatment in 3T3-L1 cells. J Diabetes Invest 2013; 4(3): 252-60.

[5] Zhu N, Pankow JS, Ballantyne CM, et al. High-molecular-weight adiponectin and the risk of type 2 diabetes in the ARIC study. J Clin Endocrinol Metab 2010; 95(11): 5097-104.

[6] Elkasrawy MN, Hamrick MW. Myostatin (GDF-8) as a key factor linking muscle mass and bone structure. J Musculoskelet Neuronal Interact 2010; 10(1): 56-63.

[7] Joulia-Ekaza D, Cabello G. The myostatin gene: physiology and pharmacological relevance. Curr Opin Pharmacol 2007; 7(3): 31015 .

[8] Pan H, Ping XC, Zhu HJ, et al. Association of myostatin gene polymorphisms with obesity in Chinese North Han human subjects. Gene 2012; 494(2): 237-41.
[9] McPherron AC, Lee SJ. Double muscling in cattle due to mutations in the myostatin gene. Proc Natl Acad Sci USA 1997; 94(23): 12457-61.

[10] Lin J, Arnold HB, Della-Fera MA, Azain MJ, Hartzell DL, Baile CA. Myostatin knockout in mice increases myogenesis and decreases adipogenesis. Biochem Biophys Res Commun 2002; 291(3): 701-6.

[11] McPherron AC, Lee SJ. Suppression of body fat accumulation in myostatin-deficient mice. J Clin Invest 2002; 109(5): 595-601.

[12] Guo T, Jou W, Chanturiya T, Portas J, Gavrilova O, McPherron AC. Myostatin inhibition in muscle, but not adipose tissue, decreases fat mass and improves insulin sensitivity. PLoS One 2009; 4(3): e4937.

[13] Mitchell AD, Wall RJ. In vivo evaluation of changes in body composition of transgenic mice expressing the myostatin pro domain using dual energy x-ray absorptiometry. Growth Dev Aging 2007; 70(1): 25-37.

[14] Zhu HJ, Wang XQ, Pan H, et al. Serum levels of the adipokine zinc- $\alpha 2$-glycoprotein are decreased in patients with hypertension. ISRN Enocrinol 2014; 374090: 1-8.

[15] Amthor H, Macharia R, Navarrete R, et al. Lack of myostatin results in excessive muscle growth but impaired force generation. Proc Natl Acad Sci USA 2007; 104(6): 1835-40.

[16] McPherron AC, Huynh TV, Lee SJ. Redundancy of myostatin and growth/differentiation factor 11 function. BMC Dev Biol 2009; 9: 24.

[17] Milan G, Dalla Nora E, Pilon C, et al. Changes in muscle myostatin expression in obese subjects after weight loss. J Clin Endocrinol Metab 2004; 89(6): 2724-7.

[18] Park JJ, Berggren JR, Hulver MW, Houmard JA, Hoffman EP GRB14, GPD1, and GDF8 as potential network collaborators in weight loss-induced improvements in insulin action in human skeletal muscle. Physiol Genomics 2006; 27(2): 114-21.

[19] Wang F, Liao Y, Li X, Ren C, Cheng C, Ren Y. Increased circulating myostatin in patients with type 2 diabetes mellitus. J Huazhong Univ Sci Technolog Med Sci 2012; 32(4): 534-9.

[20] Chow WS, Cheung BM, Tso AW, et al. Hypoadiponectinemia as a predictor for the development of hypertension: a 5-year prospective study. Hypertension 2007; 49(6): 1455-61.

[21] Ohashi K, Kihara S, Ouchi N, et al. Adiponectin replenishment ameliorates obesity-related hypertension. Hypertension 2006; 47(6): 1108-16.

[22] Chu SH, Lee MK, Ahn KY, et al. Chemerin and adiponectin contribute reciprocally to metabolic syndrome. PLoS One 2012; 7(4): e34710.

[23] Buechler C, Wanninger J, Neumeier M. Adiponectin, a key adipokine in obesity related liver diseases. World $\mathrm{J}$ Gastroenterol 2011; 17(23): 2801-11.

[24] Kern PA, Di Gregorio GB, Lu T, Rassouli N, Ranganathan G. Adiponectin expression from human adipose tissue: relation to obesity, insulin resistance, and tumor necrosis factor-alpha expression. Diabetes 2003; 52(7): 1779-85.

[25] Limdi JK, Hyde GM. Evaluation of abnormal liver function tests. Postgrad Med J 2003; 79(932): 307-12.

[26] Liu Y, Retnakaran R, Hanley A, Tungtrongchitr R, Shaw C, Sweeney G. Total and high molecular weight but not trimeric or hexameric forms of adiponectin correlate with markers of the metabolic syndrome and liver injury in Thai subjects. J Clin Endocrinol Metab 2007; 92(11): 4313-8.

[27] Wilkes JJ, Lloyd DJ, Gekakis N. Loss-of-function mutation in myostatin reduces tumor necrosis factor alpha production and protects liver against obesity-induced insulin resistance. Diabetes 2009; 58(5): 1133-43.

(C) Zhu et al.; Licensee Bentham Open.

This is an open access article licensed under the terms of the Creative Commons Attribution Non-Commercial License (http://creativecommons.org/licenses/by-nc/3.0/) which permits unrestricted, non-commercial use, distribution and reproduction in any medium, provided the work is properly cited. 